\title{
Bahir Dar City Municipal Solid Waste Potential Assessment for Clean Energy
}

\author{
Molla Asmare ${ }^{1,}$, Belachew Alelign ${ }^{2}$ \\ ${ }^{1}$ Energy System Engineering, Gazi University, Ankara, Tükiye \\ ${ }^{2}$ Environment, Forest and Climate Change Ministry, Addis Ababa, Ethiopia
}

Email address:

mollaasmare98@gmail.com (M. Asmare)

${ }^{*}$ Corresponding author

\section{To cite this article:}

Molla Asmare, Belachew Alelign. Bahir Dar City Municipal Solid Waste Potential Assessment for Clean Energy. American Journal of Energy Engineering. Vol. 7, No. 1, 2019, pp. 28-38. doi: 10.11648/j.ajee.20190701.14

Received: April 26, 2019; Accepted: May 28, 2019; Published: June 12, 2019

\begin{abstract}
Nowadays, Carbon-rich fuels are the principal energy supply utilized for powering human society, and it will be continued for the next some decades. Connecting with this, modern energy technologies are very essential to convert the available limited carbon-rich fuels and other green alternative energies into useful energy efficiently with an insignificant environmental impression. Therefore, the main objectives of this study are assessing the potential of municipal biomass solid waste for briquette production in Bahir Dar city, Ethiopia. To conduct this research, various data collection instrument tools were used to achieve the intended objectives for instance questionnaire, direct measurement, field observation and related literature based on necessity. Moreover, to confirm the reliability of the information obtained through a questionnaire, a focus group discussion was conducted with different concerned bodies. The main finding of this study shows that Bahir Dar city has the potential to generate 50.19 tons of municipal biomass solid waste per day. The collected waste was characterized as $82.5 \%$ of them is organic waste that may be converted in to clean energy (briquette and biogas) based on their sized whereas the remaining $17.5 \%$ of them were inorganic (plastics, glass, and metals) that can be resent for recycling and reuse to their original sources. Biomass-related solid municipal waste is a promising potential to utilize as a feedstock for briquette production. Besides, it has a prodigious role to reduce deforestation, land degradation, save foreign currency and reduce greenhouse gas emissions. This is because the demands of household's energy that was fulfilled with wood charcoals and fossil fuels are substituted with locally available renewable energy sources. The experimental results confirmed that all the physicochemical properties of briquette charcoal that are produced from municipal solid biomass waste were acceptable. Besides, the burning efficiency of the briquette, fanning time and carbon content determination were measured and obtained as adequate results based on the standards. Hence, it will be a possible alternative fuel for household energy using a special design stove that is available in the market. It has also played a great role in waste management and treatment system to achieve sustainable clean city developments.
\end{abstract}

Keywords: Briquetting, Municipal Solid Biomass Waste, Carbonization, Physicochemical Properties, Clean Energy

\section{Background of the Study}

Population in urban areas are increasing at an alarming rate, hence an enormous volume of waste is generated every day. In line with this, recent studies show that 1.3 billion tonnes of solid waste per year have been generated from global cities with an annual cost of $\$ 205.4$ billion [1]. The study also predicts that it will be 2.2 billion tonnes of solid waste and costs $\$ 375.5$ billion per year by $2025 \%$ [2]. This huge waste has become serious challenges for the environment and public health [3]. Even if more than half of the world municipal waste is discarded from developed countries [4], the problem is worse in developing continents like Africa [5]. Therefore, interlinking the community at large is the indispensable option to employ effective Solid waste management systems. Bahir Dar is the former capital of Gojjam province and the current capital of the Amhara National Regional State (ANRS) located in the north-western of Ethiopia. The city has more than 324,000 inhabitants 
including rural areas in 2015.

The city has been prepared a report on solid waste characterization and quantification [6]. The report confirmed that the composition \& generation rate of the waste in tone per day were residential (54), commercial (24.2), institutional (17) and street sweeping (3.56). The total wastes generated from all sectors were 98.8 tons per day that shows the residential areas are the primary generators of wastes. Thus, utilizing the municipal biomass solid wastes as potential raw materials for clean energy production and the nonbiodegradable wastes is sending back to their original source for recycling and reuses are the most promising methods to overcome the current challenges. Also, it is imperative to make the city beautiful and attractive for diverse visitors and investors.

In Ethiopia, $85 \%$ of the population lives in a rural area. In line with this, annually 44.28 million tonnes and 3.84 million of biomass fuel were utilized for domestic cooking in rural and urban areas correspondingly [7]. Further, the practice of biomass energy is expected to upsurge due to population growth, commercialization, industrialization, and urbanization development.

In addition, the utilization of inefficient energy conversion technologies and augmented application of inferior quality fuels like dung and agricultural residues are resulting in adverse impacts on health, environment and economic development of the region. This is often as a result of the wood fuel prices are snowballing from day to day and has a shortage of clean energy access.

Today, the daily volume of municipal waste of any city is snowballing interlinking with population growth, industrialization, and urbanization progress [8-9]. These challenges are also reflected in Bahir Dar owing to a deficiency of budget for modern waste management and recovery systems. Connecting with this, the city is embarked on solid waste collection service through MSEs to manage their wastes.

Municipal solid waste has been acknowledged as one of the alternative energy sources that can be applied for sustainable electricity and/or power generation [10]. Organic wastes are an ideal source of inputs for clean energy generation, particularly for briquette charcoal and biogas. Besides, utilizing these wastes has dual benefits. These are minimizing the bulky wastes in one side and reducing the associated problems like deforestation, soil erosion, land degradation and health doubts [11]. Moreover, the powder of biochar produced from biomass wastes can enhance the fertility of the soils [12].

Utilization of municipal biomass wastes as a substitute fuel for fossil and wood charcoal has environmental and ecological advantages. Some of the advantages are minimizing the emission of methane because of biological decomposition of combustible wastes that were dumped in the open area. Methane gas is one of a powerful greenhouse gas that has 30 times more environmentally destructive than $\mathrm{CO}_{2}$ [13-14]. Different studies confirmed that $20 \%$ of global warming is due to methane gas emissions. In contrary, methane gas is imperative fuels if it is trapped and manages properly. The chronic challenges of municipal waste are its heterogeneous nature and size [15-16]. Therefore, disintegrating, drying, and homogenization of the waste is compulsory before compacting [17]. Today, the most recurrently utilized method to produced clean energy from municipal solid biomass wastes (MSBW) are pyrolysis, carbonization, anaerobic digestion and gasification [18-20].

In this work, the carbonization method was implemented which is the thermal degradation of the waste in the absence of air. This is because the process is simple and increases the energy density of the carbonized materials. As well, the carbonization process is free from environmental pollution since it is carried out in a closed kiln. The general objective of this research is to assess the potential of municipal solids waste for Clean Energy.

\section{Materials, Research Design, and Methods}

\subsection{Sources and Methods of Data Collections}

Primary and secondary data gathering techniques were applied simultaneously. Primary data were collected through questionnaires, direct measurement, and Focus Group Discussion. The other method employed was field observation. It was conducted to see the actual potential of MSW collected in the city and their approaches of solid waste gathering and sorting. This further helps to triangulate the responses obtained through different instrument tools with reality. Further, observation of the landfill site and GPS reading were performed to investigate the amount of MSW dumped in the area and its coverage. As well, secondary data was gathered by reviewing different literature.

\subsection{Methods and Techniques of Sampling}

Bahir Dar city was selected purposively for this work. This is due to the rapid population growth, household energy demand, commercialization, increasing the amount of MSW from different sectors. In order to get better insight, Gishen Abay and Sefene Selam sub-cities were selected purposively according to the info obtained from sanitation, beautification and green development department of Bahir Dar city. Connecting with this, 40 residential samples were selected from higher, medium and lower income for the questionnaire and direct measurement. The income levels of the households were discussed with the sub-city concerned stakeholders before selecting the households.

Yet, there were limitations to incorporate city income profile data due to a shortage of time. The collected solid wastes from different households' levels were quantified in terms of type and size. Besides, an equal proportion of the sample was gathered from 10 hotels, 10 commercial centers, 6 juice house and cafeteria with the support of these sub cities sanitation, beautification and green development experts. 
Furthermore, to get representative data, sample collection timing is a vital factor that should be considered. In line with this, considering the economic viability and time constraints, a weekly collected residential solid waste were measured and determined whereas one day wastes were used to determine the commercial and other types of sectors. Yet, the study was performed by gathering one-time data which later will be adjusted to represent the entire period of waste collection. Data barriers are sinking by utilizing the existing experience and local knowledge. This has also economic benefits and enhancing the effectiveness of waste gathering. Different collected sample waste streams are analyzed and suitably sorted according to their origin of types. Besides, the sorted waste was quantified and recorded for the next data analysis.

Currently, in Bahir Dar city, six micro small enterprises participated in municipal solid waste collection services.
Linking with this, 15 respondents who have engaged in this service as an administrative staff were selected as the main stakeholder. This is because the administrative staffs are more educated and they have adequate information to quantify how much wastes are discarded from the working areas.

Further, to confirm the reliability of the information obtained through the questionnaire, focus group discussion (FGD) were conducted with different stakeholders. These are 2 experts from Bahir Dar city sanitation; beautification and green development department, 1 representative from all MSEs, 2 Regional energy experts and 1 audio-visual expert were selected through purposive sampling technique. Generally, a total of 86 respondents were considered in this work and the data were analyzed using SPSS software and Excel sheet.

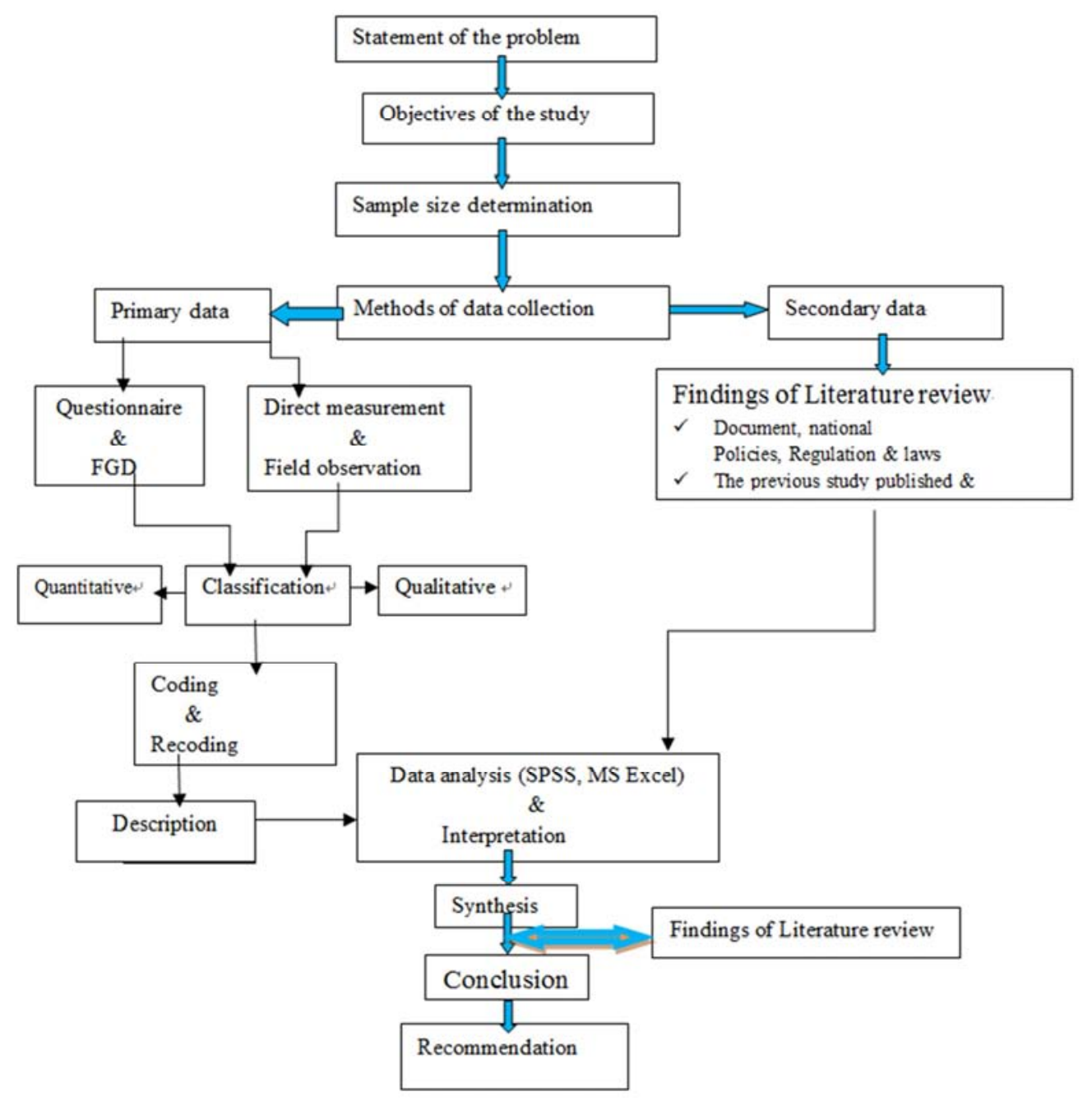

Figure 1. Research Design diagram that shows the procedures used to conduct this research.

\subsection{Methods of Briquette Production}

Charcoal briquette from municipal solid biomass waste is used as a source of alternative energy to shift the society towards sustainable economic development and environment. In Ethiopia, manually operated hand beehive briquette press and mechanized briquetting units are effectively employed in a small-scale charcoal briquetting scheme. Manual briquetting units are designed and manufactured to produce various sizes and shapes of briquettes. Yet, the commonly employed manufacturing technologies are roll presses and agglomeration technologies due to high abrasive nature of charcoal. Briquetting technologies such as piston or screw press are not suitable for briquette charcoal. In this research 
manually hand beehive briquette press machine was deployed as presented in Figure 2. This is because it is easily and manually operated with short training when coming to practice to expand the technology in off-grid society.

As well, manually hand beehive briquette press machine is produced physically strong and that have combustible characteristics comparable to wood charcoal. The briquetting process employed in this research involves the preparation of charcoal fines, the selection of appropriate binders and their composition within the char-binder mix. Furthermore, experimental work has been conducted to determine the fuel characteristics. The parameters measured and analyzed were the fixed carbon, moisture content, volatile matter, ash content, bulk density, and heating (calorific) value. The result confirmed that briquettes made from biomass municipal wastes have an acceptable quality that can be utilized in household levels. The briquettes that have acceptable physicochemical characteristics are burned and tested in my choice stoves the so-called in Amharic 'Mirichaye'. As well, critical observation and measurements were performed to investigate the speed of ignition, the time taken for complete combustion, the funning nature (whether frequent funning is required or not to keep the ember) and the tendency to selfextinguish of briquette made of MSBW. Further, the modern metal kiln was utilized to carbonize the biomass waste. The yield of charcoal obtained from the carbonization of MSBW was evaluated using standard techniques and the conversion efficiency was determined as the ratio of the total weight of biomass input to the total weight of charcoal produced.

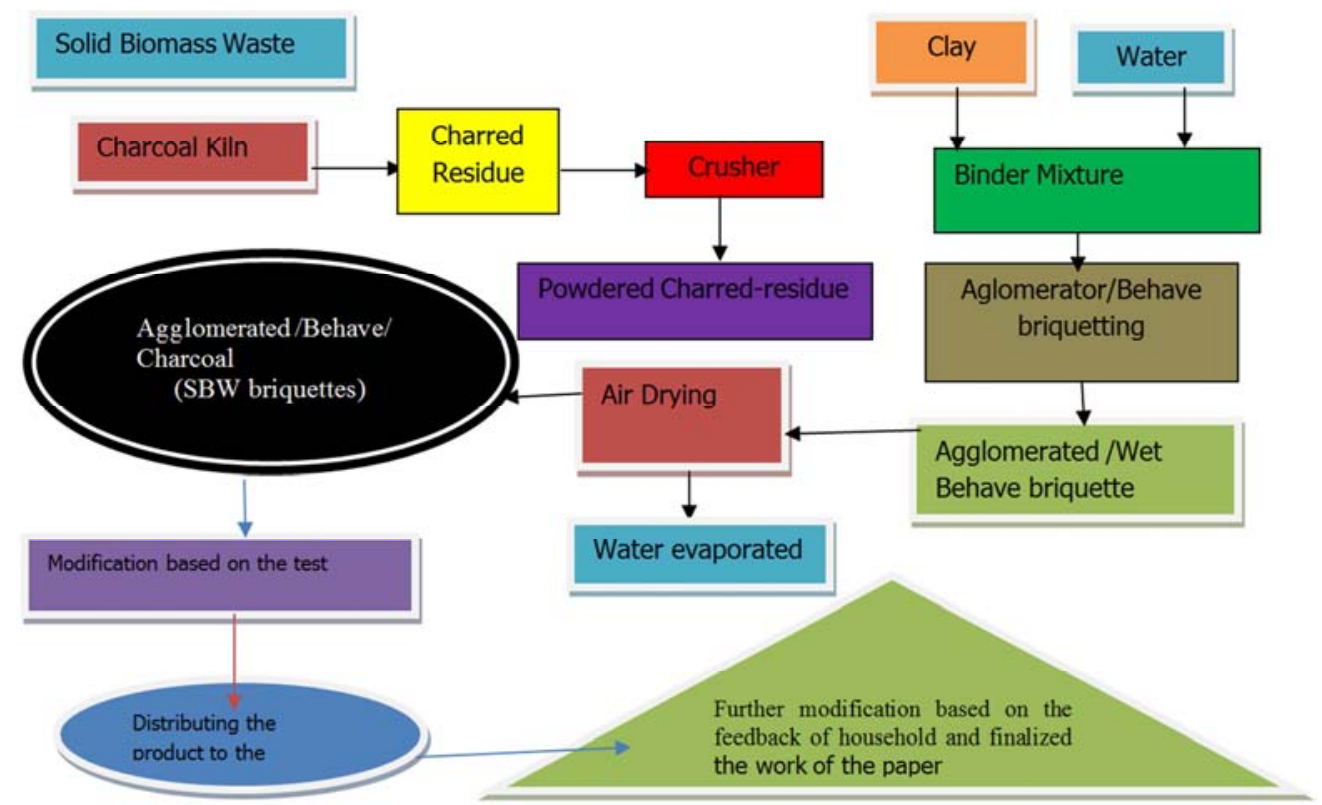

Figure 2. Schematic flow diagram that shows the hand behave and agglomerated briquette production from Solid Biomass Waste of Bahir Dar City with the quality test.

\section{Results and Discussion}

Table 1. List of Materials Available in Municipal Solid Waste Generated By Various Sectors.

\begin{tabular}{ll}
\hline NO. & Class of solid waste \\
\hline 1 & Paper and its related waste \\
& 1. Paper Bags and cartoon \\
2. Newspaper \\
3. Office and publisher residue paper \\
4. Magazines and catalogs \\
5. Phone Books and directories \\
6. Other Miscellaneous paper not mentioned \\
Glass and its related waste \\
1. Bottles, broken bottles \& glass \\
2. Broken mirrors \&pots \\
3. Ceramics \\
Metal and its related waste \\
1. Ferrous Metals \\
2. Non-ferrous metals \\
3. composite metal \\
4. metal workshop waste-powdered \\
Plastic and its related waste
\end{tabular}

\begin{tabular}{ll}
\hline NO. & Class of solid waste \\
\hline & 1. Plastic bottles for water, medicine, chemicals, juices \\
2. Different color and size festal \\
3. Miscellaneous plastic containers \\
4. Composite plastic (rubber) \\
5. Tires \\
Food and its related waste \\
1. Injera\& bread Offa \\
2. Edible fruit, potato \& onion peel \\
3. cabbage residue \\
Textiles and its related waste \\
1. Dropping /carding cotton waste \\
2. Air conditioning/ filter waste \\
3. Worn out and pieces of cloth \\
Construction \& Demolition related waste \\
1. Concrete \\
2. Asphalt Paving \\
3. Asphalt Roofing \\
4. Lumber \\
5. Gypsum Board \\
6. Rock, soil, and fines \\
7. composite cons \\
Agricultural and its related waste
\end{tabular}




\begin{tabular}{ll}
\hline NO. & Class of solid waste \\
\hline & 1. Leaves and grass \\
2. Bagasse and its residue \\
3. Pruning's and trimmings of plant \\
4. Branches and stumps \\
5. Agricultural crop Residues \\
6. Manure \\
7. Powdered charcoal \\
8. Sagatora \&pieces of wood \\
Hazardous waste \\
1. Paint and its related waste \\
2. Vehicle and equipment fluids \\
3. Used oil \\
4. Batteries \\
5. Composite household hazardous \\
6. Fluorescent lamps, cosmetics \\
7. Waste from health institute and school laboratory \\
Street sweeping \\
1. Dead animals, \\
2. Sugarcane \\
3. dust, etc. \\
\hline
\end{tabular}

\subsection{Data Analysis and Interpretation of Municipal Solid Waste in Bahir Dar City}

There are 5MSEs which were established by the government to provide job opportunity for their nations and one PLC who have engaged in the MSW service. They did not follow scientific procedures during waste collection and sorting systems due to a knowledge gap. There are no total sorting systems whereas their staff members separate metal related and mineral water plastics for additional income. As a result, hazardous waste affects their members due to a shortage of technical training. They provide weekly service for residential, twice per day for Level A, 2 day per week for level $\mathrm{B}$, and 3 days per week for level $\mathrm{C}$ organization. This structure is working for all association. The amount of MSW collected and dumped by 4 MSEs are $92 \mathrm{~m}^{3}$ per day $\left(33,120 \mathrm{~m}^{3} /\right.$ year $)$ i.e. three times the car size $\left(8 \mathrm{~m}^{3}\right)$ for each association. Averagely, they are doing the activity three times in a day with $8 \mathrm{~m}^{3}$ size car per association. The data obtained shows; they have gathered averagely from residential with service $100 \mathrm{~kg}$ and single residential $40 \mathrm{~kg}$ MSW per week per house. When coming to the figure annually, it becomes $4800 \mathrm{~kg}$ and $960 \mathrm{~kg}$ MSW per residential respectively. Currently, they are not beneficiary from this job but they have a dream to change their lives within the near future. They have a future plan to use this MSW as input for biogas and charcoal briquette. However, they have a knowledge gap in how a briquette and a biogas technology are implemented.

Table 2. Municipals solid waste dumped in the notified area by MSEs.

\begin{tabular}{|c|c|c|c|c|c|c|}
\hline NO. & MSES & Keble \& zone & MSW dumped in $\mathbf{M}^{3} /$ day & $\begin{array}{l}\text { MSW dumped in } \\
M^{3} / \text { year }\end{array}$ & $\begin{array}{l}\text { MSW dumped in } \\
\mathrm{kg} / \text { year }\end{array}$ & $\begin{array}{l}\text { MSW dumped in } \\
\text { tone /year }\end{array}$ \\
\hline 1 & MSE-1 & Shim abo (8) & 24 & 8640 & 7430400 & 743.04 \\
\hline 2 & MSE-2 & Shimbitie (13) & 32 & 11520 & 9907200 & 990.72 \\
\hline 3 & MSE-3 & Belay Zeleke $(7,17)$ & 22 & 7920 & 6811200 & 681.12 \\
\hline 4 & MSE-4 & Hidar-11 & 20 & 7200 & 6192000 & 619.2 \\
\hline 5 & Total & & 98 & 35280 & 30340800 & 3034.08 \\
\hline
\end{tabular}

Source: Field Survey, 2015

\subsection{Municipal Solid Wastes in Different Sectors}

Residential waste generated by households living either in single-family houses or multi-family buildings may contain organic waste from the kitchen and gardens, recyclable waste (plastics, paper, cans, etc.), non-recyclable waste (that has no recycling value), and hazardous waste (batteries, some oils, etc.). Usually, the municipality is responsible for collection and disposal of such waste, thus it is treated as municipal waste. Moreover, wastes that are related to papers, carton, agricultural wastes, crop residues, and rubbish are also considered. Food and Non-hazardous commercial waste generated by the businesses sectors are considered as municipal waste. Yet, it is not considered in this study. This is often as results of the goal of the study were more concentrated in biomass-related wastes. The amount of waste obtained from hotels, commercial centers, juices house and cafeterias through direct measurement from the selected subcities are present in a bar graph.

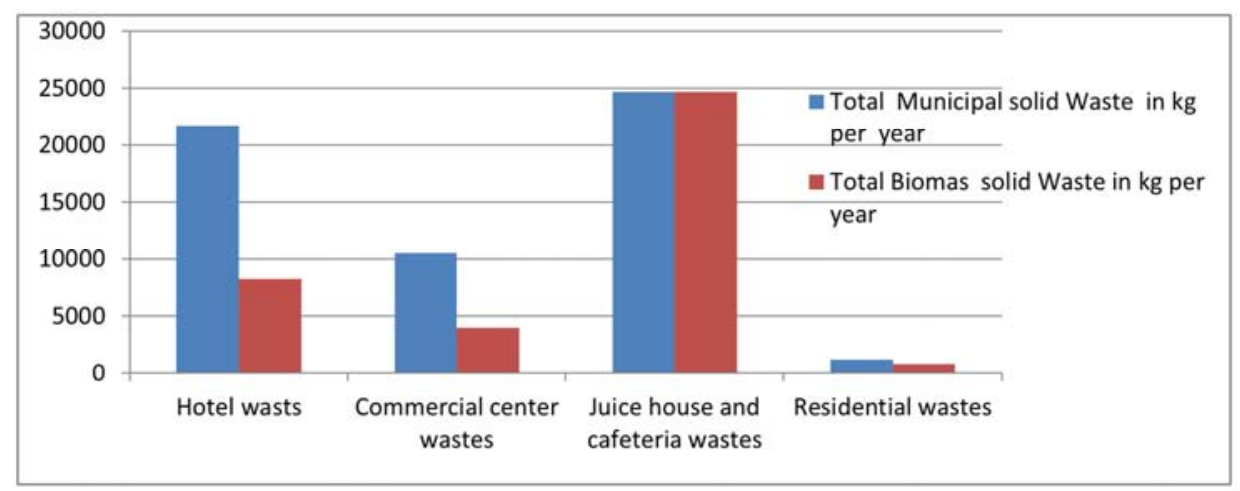

Source: Field Survey, 2015

Figure 3. Municipals solid waste collected through direct measurement (DC). 
As can be seen from the figure, the wastes generated from juice house are biomass wastes that can be utilized as a feedstock for clean energy production. As well, when considering the total inhabitants, the residents are the primary waste generators.

\subsection{Industrial Waste}

There are some industries in the city. However, most of these industries waste is not biomass, hence only the Bahir Dar textile share company was considered. In this factory, the total amount of waste discarded particularly cotton related waste namely dropping (carding) and air conditioning (filter) waste. According to the information obtained from Bahir Dar textile Share Company corporate system support core process general manager, all the waste types removed from the company is not quantified still now. Yet, the solid waste consists of paper, carton, air conditioning, dropping, metal workshop waste, plant leaves, branches, and Sagatora waste. However, cotton-related waste is quantified daily in two shifts. And also, he added more, the collected waste is incinerated with chimney build by the company but there is a trial to compact the solid waste into uncarbonized briquette from paper, cotton and Sagatora wastes. Furthermore, Bahir Dar textile share company research and development study expert said that all the uncarbonized briquette produces with simple hand pressing machines and burned well in the ordinary charcoal stove but there is not a farther analysis on the physicochemical properties of fuel like indoor air quality due to emissions, calorific value, carbon content, moisture, and density. Most of the waste is recycled and reused in the company; however, the total amount of cotton waste removed as a waste averagely in two days in a single shift recorded was $336 \mathrm{~kg}$. This means annually $120960 \mathrm{~kg}$ (12.096 tonnes) cotton related waste is discharged from the company. Furthermore, he said that it is difficult to quantify the total amount of cotton-related waste within a week, even a month since the amount of waste discarded is varying based on the types of input quality and the working time. This is because the generator covers only basic operators like spinning and dying machines. In line with this, the data obtained from different literature shows that the total amount of solid waste removed from the company was 54 ton/month or 648 ton annually. Hence, the company has plenty of potential raw materials to generate clean energy.

Table 3. Distribution of waste production among selected waste streams in Gish Abay and Sefene Selam sub-city.

\begin{tabular}{llll}
\hline Waste stream & Total of mount MSW kg/d & percentage & Total of mount SBW kg/d \\
\hline Residential & 996 & 37.73 & 666.6 \\
Commercial & 292 & 11.06 & 110.9 \\
Industrial & 336 & 12.73 & 336 \\
Juice house & 411.6 & 15.59 & 411.6 \\
Hotels & 604.4 & 22.89 & 229.67 \\
Total & 2640 & 100 & 19.15 \\
\hline
\end{tabular}

Source: Field Survey, 2015

\subsection{Quantification of Municipal Solid Waste}

According to different reports more than $74 \%$ of the municipal solid wastes are organic that can be applied in briquette manufacturing and anaerobic digester. From these, the residential waste constitutes above $55 \%$ which is the primary waste generators. Besides, it is estimated that the population will doubles in 2022 hence the waste generated will also be doubled. Therefore, it may be difficult to manage it unless it will be changed this huge potential to clean energy. The waste generators are accumulating the solid waste within bags and wait till the collectors come up to a week. This is because for households they were collecting the wastes weekly whereas for hotels based on their agreements. This is one of the critical issues for human health. They are also responsible to pay a monthly fee with the water bill to the service provider. Yet, according to this finding, it is so low.

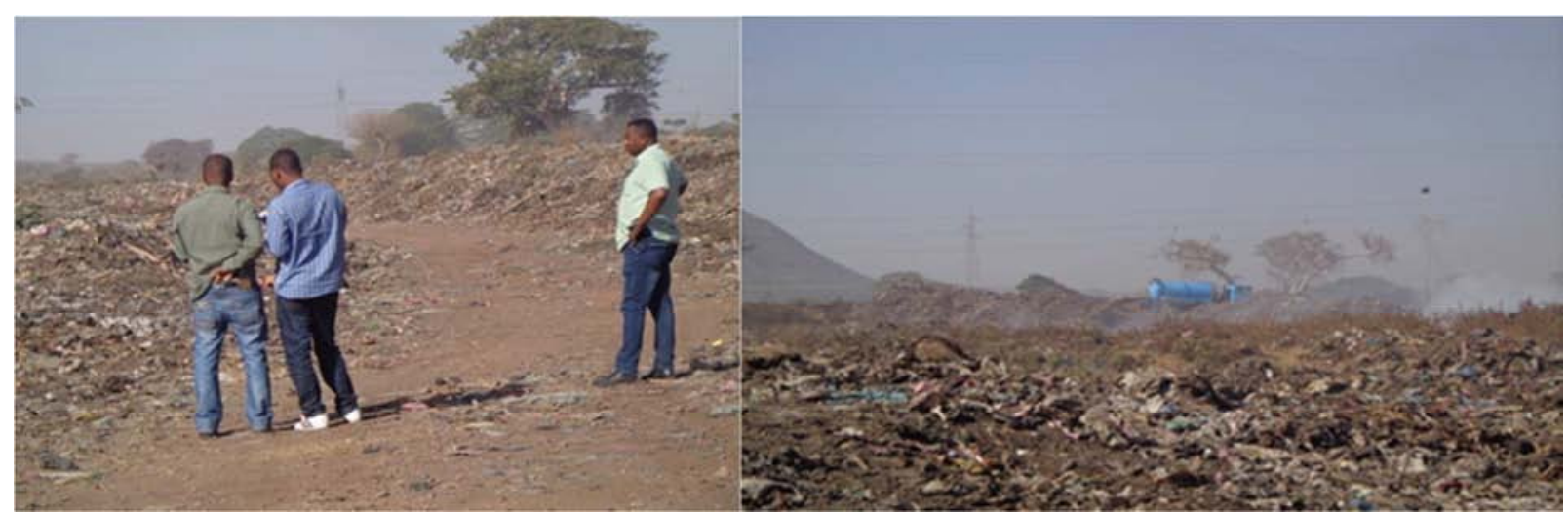

Figure 4. Bahir Dar city municipal waste dumped area. 


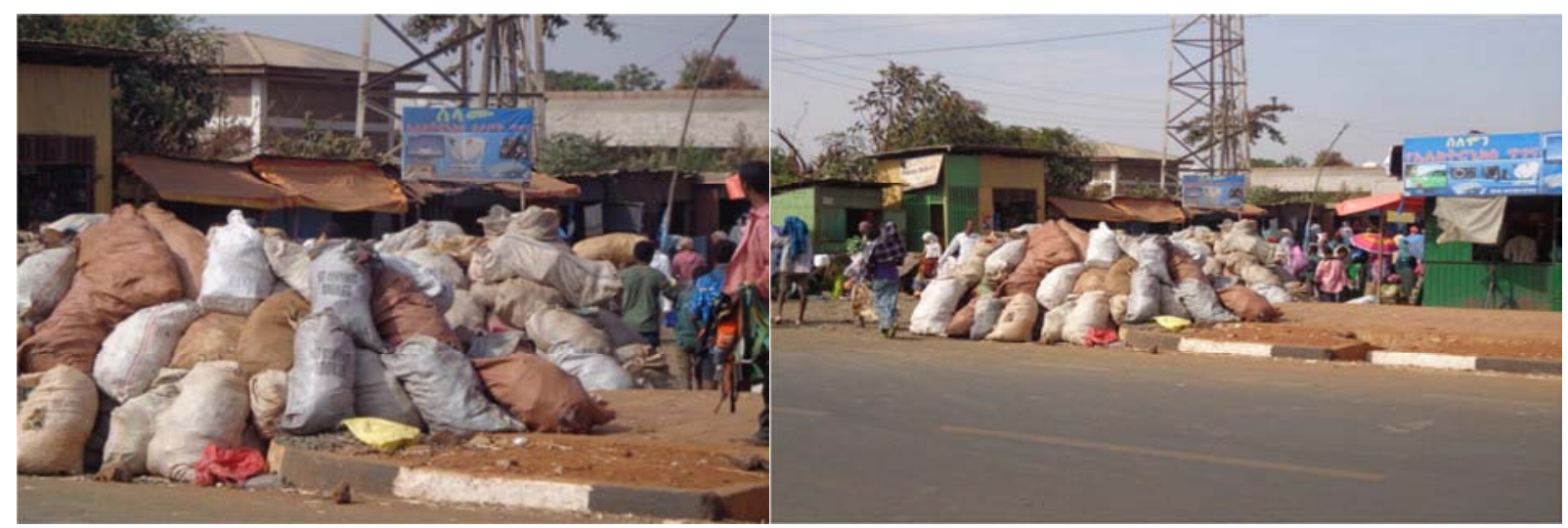

Figure 5. Temporary transfer stations.

Solid waste is collected from the source using pushcarts to the temporary transfer stations that are not legally approved sites on the street sides. There are no standard transfer stations in the city hence the door to door collection covers all residences, commercials and some institutions based on the agreement. However, all health care and industries follow their way of removal. Most of them burn the waste; while some others dispose it to the nearby river the Blue Nile or Lake Tana. Hence, the city should be enforced for these institutes to keep the river and Lake Tana as her/his property and should put written rules and regulation for punishment. Moreover, the city administration should be established local law on municipal solid waste by discussing with the community, the institute leader, industry owners, and nongovernmental organization.

\subsection{Waste Recycling and Recovery System in the City}

In the city, solid waste recycling is insignificant $(<1 \%)$. Most of them are disposed to the open field dumping site. Yet, the city administration has established a Green vision organization that prepared compost from organic waste and providing training for any voluntary and interested individual and organization. Furthermore, Dream light has also started selling used papers to paper recycling industries. There are also some scavengers who collect some goods from waste and resale or recycle it at a small-scale level.

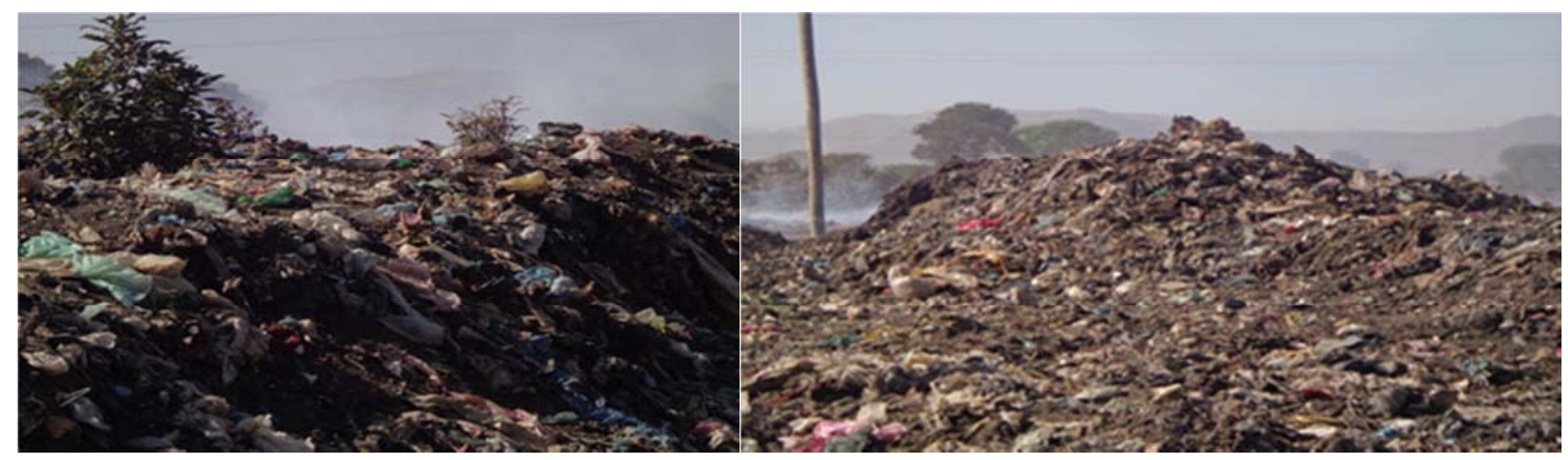

Figure 6. Partial view of the solid waste disposal site.

\subsection{Focus Group Discussion Analysis}

According to the FGD response, before the establishments of 5 MSEs namely Green vision, Yifetsemal Kalu, Sira Lehiwote, Tigist, and her friend, Emenshi and Mokennen there was only one private limited company, which is called Dream Light. This PLC provided solid waste collection service for households, commercial center, hotels, industries, juice house, restaurants and cafeteria, a governmental and nongovernmental organization. This local private company has given the responsibility to collect and transport the city's waste by receiving the service fee directly from the beneficiary. Since there has not any competitor, the quality of the private has decreased over time. On the other hand, they became highly interested to gain more profit and tried to raise their monthly service fee from 8.00 birr to 12.00 birr $(\$ 0.39$ to $\$ 0.58$ ) for households. Similarly, the higher increment was applied in commercials and related organizations without any discussion with the beneficiary and the municipality. As a result, the service users highly complained about this sudden change of the service fee to the municipality. Hence, the municipality planned to search for other alternative solutions. Later, 5MSEs with the integration of other stakeholders were established. Besides, the purpose of organizing these MSEs has multifaceted objectives. The immediate objective is for economic purposes, that is creating a job opportunity for lowincome people on the street. The $2^{\text {nd }}$ is to keep the cleanliness of the city by creating more competitors. Since the city is one of the major tourist's destination sites in the country, it has 
also a benefit in changing the image of the city by minimizing those people who lived on the street. Furthermore, the main actors or supporters in the process of organizing the MSEs are the city that covers $50 \%$ of the cost for transportation and technical training whereas the remaining fee is covered by the beneficiary collected through water bill. The money was used for salary for their members and to deposit in their accounts.

Further, before 2009 the total expense used for MSW management was totally covered by the city. And the cost was incorporated in its annual budget; which was a big burden for the city administration. Yet, this has been changed since the waste generators have been shared costs to some extent.

Today, each household are responsible to pay about 8ETB (\$0.8) per month as a service fee with a water bill to the associations who engaged in MSW services. And also, the service fee for commercial centers ranges from 10 to 750 ETB ( $\$ 1$ to $\$ 75$ ) per month. Even though the service fee is set by the service providers and takers, there is no any chance to increase the fee from the already set. The reason is that the community still lacks knowledge and awareness of the importance of proper solid waste management. Still, there are gaps between the fee and the costs of solid waste management. Some of the gaps are covered by the city administration and the company, which becomes a big challenge for the company to work effectively and efficiently.

The location of the dumped area is located $7 \mathrm{~km}$ far from Bahir Dar city based on the old master plan. However, peoples are living near to the dumped area less than $1 \mathrm{~km}$. This may have a negative impact on the people and animals living surrounding the area. As a result, farmers are losing their animals because of eating plastic bags and undigested in organic materials since there is no treatment or segregation at the disposal site. This dumped area covers 22 hector lands. Due to such problems, the city administration with the support of the World Bank has a plan to build a modern landfill and started the work in this year. As that time, these chronic problems will be solved and the city beauties are increased as a result the foreign currency income of the city is also increased and its vision and mission are achieved. As well the MSEs who have engaged in this work will be benefited better than the current one. However, the focus group discussant hasn't any information about the way how this area is selected.

Additionally, about $70 \%$ (69 tons /day) of the daily generated MSW is collected and disposed to the disposal area and also about $2 \%(2$ ton $/ \mathrm{d})$ of waste is used to produce compost. Yet, the remaining $27.6 \%$ (27 ton/d) MSW is not collected by the service providers. Hence, it is either burned or buried in their compound or disposed to lakesides or into the river.

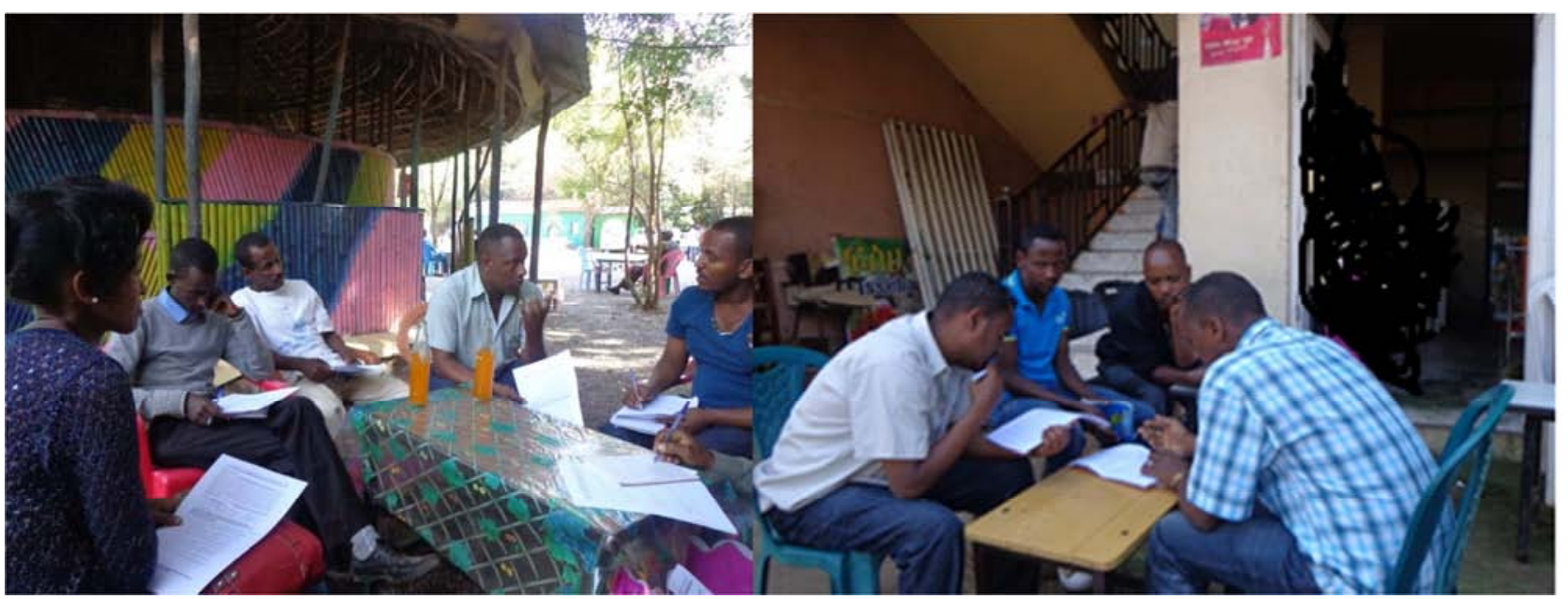

Figure 7. Photos that show FGD participates.

Today, according to the annual report of the city in 2014 indicates that annually, $101,000 \mathrm{~m}^{3}$ municipal solid wastes (MSW) are available in the city. From this $70 \%$ of them is collected and dumped in the notified area through 5 MSEs and dream light. To continue this work, as usual, it is difficult for the city administration since the bulk of MSW is increasing with population and economic development. The future plan of the city is implementing waste management hierarchies: $1^{\text {st }}$ source reduction, reuse, recycling, minimization, recycle and recover valuable resource from MSW in the form of energy. Finally, the focus group discussant has said that we need the support of water and energy bureau to provide training on methods of charcoal briquette production and which types of
MSW is feasible for this purpose. And also, the government and nongovernmental organization should be allocated sufficient budget and different stakeholder should also be participated and invested in this work.

\subsection{Quantification of Municipal Solid Biomass Waste}

The available residential wastes were measured using digital balance and achieved averagely $800 \mathrm{~kg}$ per week. According to the info obtained from Bahir Dar city administration and CSA 2007 reports, the average family size of the city is 4.4. Hence, based on the 2014 population, the residential waste generation per capita per day is determined as follows: 


$$
\begin{gathered}
\text { Residential per capita per day }=\frac{800 \mathrm{~kg}}{(40 * 2.5 * 4.4 * 7 \text { days })}=\frac{0.2597 \mathrm{~kg}}{\text { cap } / \text { day }} \\
\text { Residential waste generated per day }=0.2597 * 324,000=84142.8 \mathrm{~kg} / \mathrm{day} \sim 84 \text { tons } / \text { day }
\end{gathered}
$$

From 84 tons/day of residual waste, $37.93 \%$ of them are biomass waste that can be converted into briquette.

$$
\text { The available bomas waste for briquette }=84 * 0.3793=31.86 \text { tons } / \text { day }
$$

Hence, residential biomass wastes have a huge potential that can be consumed as a substitute for household energy that was fulfilled with fossil fuels and wood charcoal.

Similarly, according to the city solid waste management reports [6], the amount of biomass waste obtained from 800 hotel and 35 juice houses is calculated as;

$$
\text { Besides, from Bahir Dar textile share company } 0.34
$$$$
\text { The available bomas waste for Hotel }=\left(\frac{604.4 * 835}{16}\right) * 0.1309=6.33 \text { tons } / \text { day }
$$$$
\text { The available bomas waste from commercial centers }=\left(\frac{292 * 6000}{10}\right) * 6.32 \%=11.1 \text { tons } / \text { day }
$$$$
\text { The available bomas waste from juice house }=\left(\frac{411.6 * 35}{6}\right) * 23.46 \%=0.56 \text { tons } / \text { day }
$$
tons/day biomass wastes were obtained. Therefore, Bahir Bar city has a huge potential raw material which accounts 50.19tons for clean energy production through briquetting and anaerobic digestion processes. MSBW is a promising substitute fuel for household energy, particularly for wood charcoal. Besides, they have imperative roles to reduce deforestation, land degradation, greenhouse gas emissions and also to save foreign currency. Yet, currently, they are discarded as unnecessary materials.

\subsection{Experimental Result/Physicochemical Properties}

For this study, six samples of MSBW, each $10 \mathrm{~kg}$ was taken from the two sub-cities for trial. These are 01A-powder charcoal, 01B-Papyrus, 01C-Fuirts Peel, 01D-Cartilage waste, 01E-Dropping waste and, 01F- Bagasse. These raw materials were carbonized using a metal kiln that is designed by the energy bureau for wood carbonization purpose. The conversion efficiency of these biomass waste was obtained $25 \%$ i.e. $2.5 \mathrm{~kg}$ of charcoal is obtained averagely. Then it was crushed and making powered with tradition mill and mixed with clay at a ratio of 1 to 4 . Then the mixture is molded into briquette using hand beehive pressing machine. Finally, the fabricated briquettes were characterized to use as a substitute fuel for household energy.

According to this finding, the average heating value and fixed carbon content of powdered charcoal are higher than all the samples considered which is above the acceptable value as presented in figure 8 and table 4 . As well, among all samples, the volatile matter, moisture content and ash content is lowered. Further, the volatile matter of fruit peel is higher compared with other samples. As well, when comparing the ash contents, the cotton dropping obtained from Textile Company is higher over others. The bagasse takes the second in calorific value and fixed carbon content next to powered charcoal considered in this study. Yet, its volatile matter is higher than the powdered charcoal.

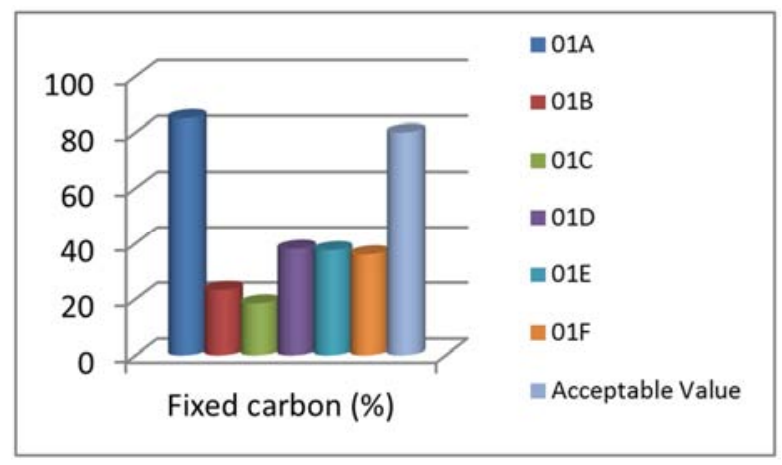

a) Fixed carbon

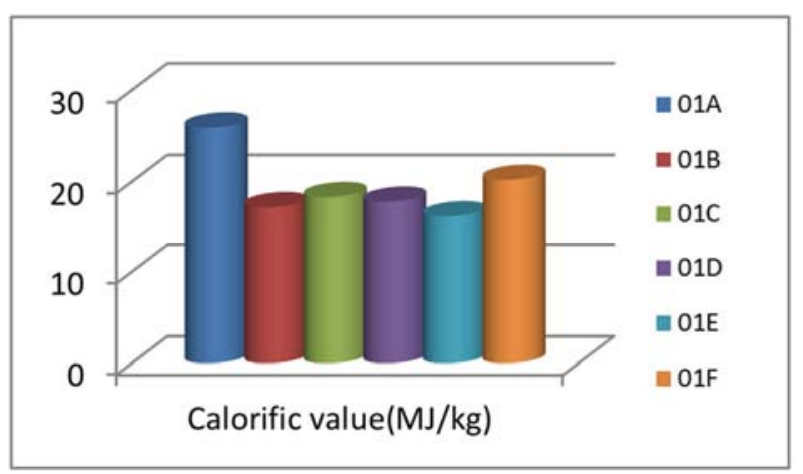

b) Calorific value

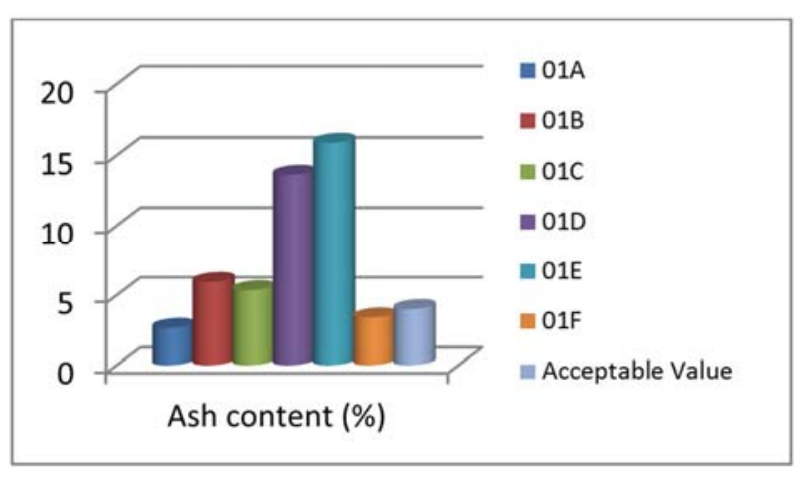

c) Ash content 


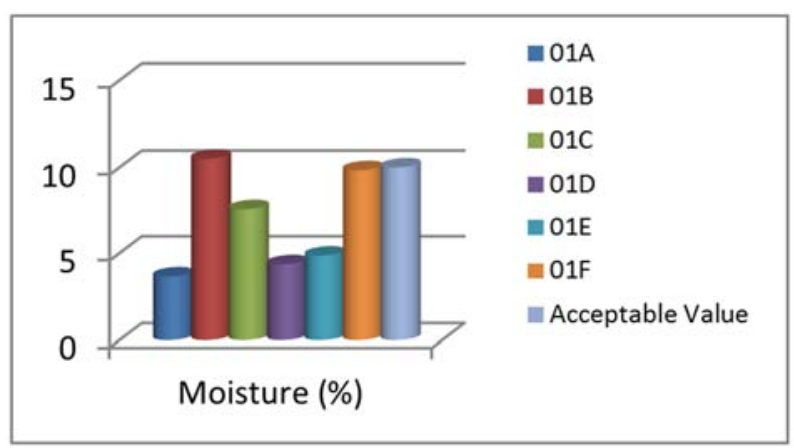

d) Moisture content

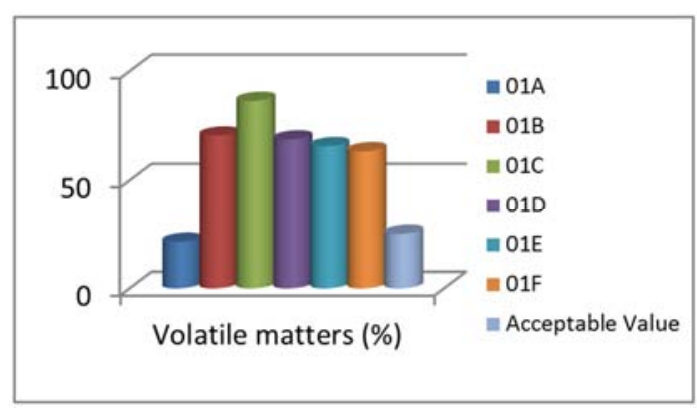

e) Volatile matters.

Figure 8. Comparison of the physicochemical properties of selected samples.

Table 4. Experimental results of psycho-chemical characteristics of produced briquettes/charcoal powder from MSB.

\begin{tabular}{llllllll}
\hline \multirow{2}{*}{ Measure items } & \multicolumn{2}{l}{ Types of Samples } & & & & \\
\cline { 2 - 8 } & 01A & 01B & 01C & 01D & 01E & 01F & Acceptable value \\
\hline Fixed carbons (\%) & 85.00 & 23.23 & 18.36 & 37.98 & 37.50 & 36.00 & $75-80 \%$ \\
Calorific value (MJ/kg) & 25.88 & 17.20 & 18.30 & 17.80 & 16.20 & 20.20 & - \\
Ash content (\%) & 2.66 & 5.94 & 5.36 & 13.62 & 15.89 & 3.4 & $3-4 \%$ \\
Moisture (\%) & 3.66 & 10.50 & 7.58 & 4.36 & 4.86 & 9.84 & $10 \%$ max. \\
Volatile matters (\%) & 21.32 & 70.50 & 86.39 & 68.70 & 65.64 & 63.32 & $20-25 \%$ \\
\hline
\end{tabular}

The moisture content and calorific value of the prepared briquette were measured and determined at the laboratory of Ethiopia energy authority. The burning efficiency of the briquette, fanning time and carbon content determination were also performed and obtained in good quality. The experimental result disclosed that the briquette fabricated from municipal organic waste is the best solution both too utilized as an alternative clean energy source and to manage and treat the waste systems of the city. This is because the physicochemical and the burning efficiency of the briquette were acceptable and can be used as a household's energy using a special design stove that is available in the market for this purpose.

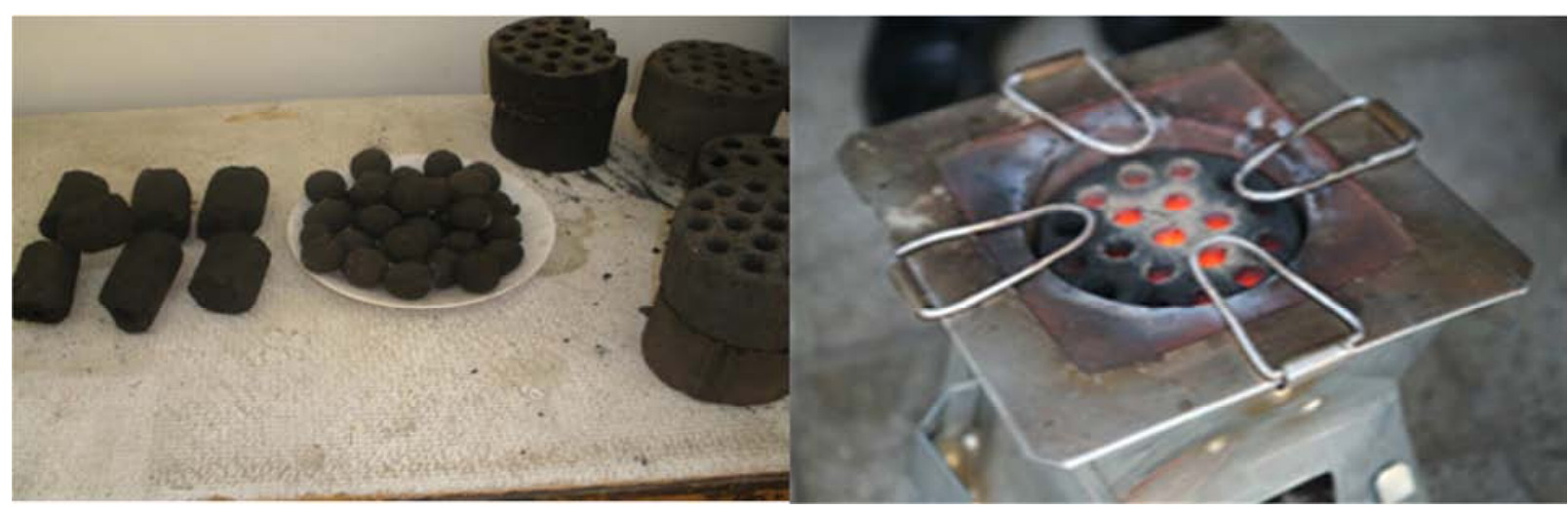

Figure 9. Sample Produced briquettes.

\section{Conclusions}

Bahir Dar city is one of the big cities in Ethiopia that has the potential to generate 50.19tons of municipal biomass solid waste per day. Biomass-related solid municipal waste is a promising potential to utilize as a feedstock for briquette production. Besides, it has a prodigious role to reduce deforestation, land degradation, save foreign currency and reduce greenhouse gas emissions. This is because the demands of household's energy that was fulfilled with wood charcoals and fossil fuels are substituted with locally available renewable energy sources.

The experimental results confirmed that all the physicochemical properties of briquette charcoal that are produced from municipal solid biomass waste were acceptable. Besides, the burning efficiency of the briquette, fanning time and carbon content determination were measured and obtained as adequate results based on the standards. Hence, it will be a possible alternative fuel for household energy using a special design stove that is available in the market.

\section{Conflicts of Interest}

The author has no conflict of interest. 


\section{Acknowledgements}

We would like to say thank you for Amhara National Regional State Energy and Mines Agency in support of the finance and transport services. Moreover, we thank you all participate in this research in different aspects.

\section{References}

[1] D. Hoornweg and P. Bhada-Tata, "A global review of solid waste management," 2012.

[2] D. Moya, C. Aldás, G. López, and P. Kaparaju, "Municipal solid waste as a valuable renewable energy resource: A worldwide opportunity of energy recovery by using Waste-ToEnergy Technologies," in Energy Procedia, 2017.

[3] P. H. Brunner and H. Rechberger, "Waste to energy - key element for sustainable waste management," Waste Manag., 2015 .

[4] H. Jouhara et al., "Municipal waste management systems for domestic use," Energy, 2017.

[5] UNEP, "An Overview of our Changing Environment," in Geo Year Book 2004/5, 2005.

[6] Bahir Dar City administration, "Solid Waste Characterization and Quantification of Bahir Dar City for the Development of an Iswm Plan," no. June 2010.

[7] R. To, T. H. E. Ethiopian, and B. E. Sector, "Biomass Energy Sector".

[8] A. U. Zaman and S. Lehmann, "Urban growth and waste management optimization towards 'zero waste city," City, Cult. Soc., 2011.

[9] World Energy Council, "World Energy Resources: Waste to Energy," 2016.

[10] W. P. Q. Ng, H. L. Lam, P. S. Varbanov, and J. J. Klemeš, "Waste-to-Energy (WTE) network synthesis for Municipal Solid Waste (MSW)," Energy Convers. Manag., 2014.
[11] A. Karagiannidis, G. Perkoulidis, and A. Malamakis, "DEVELOPMENT OF A METHODOLOGY FOR THE EVALUATION OF DIFFERENT MUNICIPAL SOLID WASTE ANAEROBIC DIGESTION TECHNOLOGIES," in environmental sanitary engineering center, 2006, no. December 2006.

[12] M. H. Duku, S. Gu, and E. Ben Hagan, "Biochar production potential in Ghana - A review," Renewable and Sustainable Energy Reviews. 2011.

[13] A. St-Pierre et al., "Methane fluxes show consistent temperature dependence across microbial to ecosystem scales," Nature, 2014.

[14] V. Talyan, R. P. Dahiya, S. Anand, and T. R. Sreekrishnan, "Quantification of methane emission from municipal solid waste disposal in Delhi," Resour. Conserv. Recycle., 2007.

[15] I. Markov, S. Varone, and M. Bierlaire, "Integrating a heterogeneous fixed fleet and a flexible assignment of destination depots in the waste collection VRP with intermediate facilities," Transp. Res. Part B Methodol., 2016.

[16] A. Demirbas, "Waste management, waste resource facilities, and waste conversion processes," Energy Convers. Manag., 2011.

[17] P. Križan et al., "Briquetting of municipal solid waste by different technologies in order to evaluate its quality and properties," Agron. Res., 2011.

[18] D. Chen, L. Yin, and H. Wang, "Pyrolysis technologies for municipal solid waste," Waste Manag., vol. 34, no. September, pp. 25-34, 2014.

[19] J. Malinauskaite et al., "Municipal solid waste management and waste-to-energy in the context of a circular economy and energy recycling in Europe," Energy, 2017.

[20] D. Czajczyńska et al., "Potentials of pyrolysis processes in the waste management sector," in Energy Procedia, 2017. 